\title{
The effect of previous obstetric interventions in the outcome of placenta previa
}

\author{
Deepti Bhaskaran Nair ${ }^{1}$, Lekshmi Murukesan ${ }^{2 *}$, Sangeetha Menon ${ }^{3}$
}

\begin{abstract}
${ }^{1}$ Department of Obstetrics and Gynecology, KJK Hospital and Research centre, Trivandrum, Kerala, India ${ }^{2}$ Department of Obstetrics and Gynecology, Sree Gokulam Medical College, Thiruvananthapuram, Kerala, India ${ }^{3}$ Department of Obstetrics and Gynecology, Indira Gandhi Medical College, Kollam, Kerala, India
\end{abstract}

Received: 08 October 2017

Accepted: 14 October 2017

\section{*Correspondence:}

Dr. Lekshmi Murukesan,

E-mail: lekshmi.ravi@gmail.com

Copyright: (c) the author(s), publisher and licensee Medip Academy. This is an open-access article distributed under the terms of the Creative Commons Attribution Non-Commercial License, which permits unrestricted non-commercial use, distribution, and reproduction in any medium, provided the original work is properly cited.

\begin{abstract}
Background: Increase in the incidence of prior caesarean section and other obstetric interventions have contributed to a rise in the number of pregnancies complicated by placenta previa and its associated adverse maternal and perinatal outcome. This study compared the incidence of placenta previa, associated risk factors, placental position, complications and feto-maternal outcome in scarred and unscarred uterus. Objective of present study was to compare the antepartum, intrapartum and postpartum complications in placenta previa between previously scarred uterus and unscarred uterus.

Methods: This was a prospective "nested" case control study for a period of 18 months, conducted at SAT Hospital, Medical College, Thiruvananthapuram with diagnosed cases of placenta previa with previously scarred uterus and without a previously scarred uterus. Statistical method used for analysis was chi-square test and students test wherever appropriate. $\mathrm{P}<0.05$ was taken as significant.

Results: In this study of 242 patients, there were 134 in the case group and 108 in the control group. The major types of previa were seen in the previously scarred uterus compared to unscarred uterus $(55.9 \%$ versus $37.9 \%)$. Occurrence of recurrent APH (58.9\% Vs 41.6\%), postpartum haemorrhage (69.4\% Vs 48.1\%), adherent placenta (5.9\% versus $0 \%$ ) and need for additional operative procedures $(66.4 \%$ versus $53.7 \%)$ including obstetric hysterectomy, need for blood transfusions, postoperative complications $(9.7 \%$ versus $1.8 \%)$, long postoperative hospital stay were all significantly associated with cases of placenta previa in previously scarred uterus.

Conclusions: The primary caesarean rate needs to be reduced in order to reduce future pregnancy problems like adherent placenta and caesarean hysterectomy. Such patients need early referral and management in a tertiary health centre with all facilities available for a better maternal and neonatal outcome.
\end{abstract}

Keywords: Adherent placenta, Placenta previa, Scarred uterus

\section{INTRODUCTION}

Placenta previa is an obstetric complication occurring in the second and third trimester of pregnancy where placenta is inserted partially or wholly in the lower uterine segment. ${ }^{1,2}$ Placenta previa occurs in $0.3-0.5 \%$ of all pregnancies and is a leading cause of antepartum haemorrhage. ${ }^{3}$ Placenta previa is related to abnormal vascularisation of the endometrium caused by scarring or atrophy from previous trauma, surgery or infection. These factors may reduce the differential growth of lower segment which results in upward shift in placental position as pregnancy advances. ${ }^{4}$ The complication of varying degrees of adherent placenta, the risk of which 
increases linearly with the number of previous caesarean sections, can be quite disastrous.

Another very important factor to be considered is the total number of bed days for the mother in the hospital. In developing countries like India, the cost of long duration of hospital stay may not be affordable for a large proportion of patients.

Studies have shown that with previous obstetric interventions like caesarean section, induced abortion etc, there is not only an increased risk of adherent placenta but also increased risk of previa, greater incidence of antepartam haemorrhage and earlier termination of pregnancy, thereby causing greater morbidity to both the mother and the baby.

This study aims at comparing two groups of patients with placenta previa- first those with previous obstetric intervention and the other with no obstetric intervention and the other with no obstetric intervention. A comparison of pregnancy outcome in both groups is made and statistically analyzed.

\section{METHODS}

This was a prospective "nested" case control study for a period of 18 months, conducted at SAT Hospital, Medical College, Thiruvananthapuram. In the present study, there were a total of 242 patients. 134 patients belonged to the case group (previous scarred uterus) and 108 cases belonged to the control group (unscarred uterus).

Case group: Those patients who delivered in the Hospital with placenta previa and a previous scarred uterus. The reasons for scarring were - previous LSCS, previous hysterotomy, previous myomectomy, manual removal of placenta, D and C and endometrial biopsy.

Control group: Those patients with placenta previa and unscarred uterus.

The following parameters were examined and compared between the two groups. Socio demographic profile, Parity, Type of previa, History of previous interventions, Obstetric profile Incidence of APH, Gestational age at delivery, Mode of delivery, Intrapartum and postpartum problems (like presence of PPH, severity, Medical Mx, Surgical Mx, Blood transfusions, intra-op complications) and postoperative hospital stay.

A detailed history followed by clinical examination was done. The ultrasound scan was also noted to confirm findings of placenta previa. The mode of deliveryvaginal, elective or emergency caesarean section was noted.

During caesarean section, the type of placenta was confirmed again. The various intra and postoperative complications were also noted.

\section{Statistical analysis}

Statistical method used for analysis was chi-square test and students test wherever appropriate. $\mathrm{P}<0.05$ was taken as significant. Data entry was done using Microsoft excel and analysis done using SPSS. Consent was obtained from the patients included in the study.

\section{RESULTS}

In the present study, there were a total of 242 patients. 134 patients belonged to the case group (previous scarred uterus) and 108 cases belonged to the control group (unscarred uterus)

\section{Socio-demographic profile}

Referral status and socioeconomic status was comparable between the 2 groups. Mean maternal age for the scarred group were 28.41 and that of the non-scarred group were 25.81 and the difference was statistically significant. Mean maternal age for cases were 28.41 and that of controls were 25.81 and the difference was statistically significant. (P value $0.000, \chi^{2} 4.47$ ) (Table 1).

Table 1: Socio-demographic profile.

\begin{tabular}{lll} 
Parameter & P value & \multicolumn{1}{c}{$\chi^{2}$} \\
Referral status & 0.16 & 0.475 \\
\hline Maternal age & 0.00 & 4.47 \\
SES & 0.18 & 0.416 \\
\hline
\end{tabular}

\section{Parity}

Out of the 242 cases of placenta previa taken, 153 $(63.2 \%)$ were parous whereas $89(36.8 \%)$ cases were primigravida. Among the parous women, 119 (77.8\%) were in the case group (with previous obstetric interventions) as compared to $34(22.2 \%)$ in the control group (without any interventions).

\section{Previous obstetric interventions}

The reasons for scarring are outlined in table 2. Among the various obstetric interventions, previous caesarean section was found to be the most important predisposing factor, followed by $\mathrm{D}$ and $\mathrm{C}$.

Table 2: Previous obstetric interventions.

\begin{tabular}{|lll|}
\hline Intervention & Number & Percentage \\
\hline Previous 1 CS & 62 & 46.3 \\
\hline Previous 1 CS + D and C & 12 & 8.9 \\
\hline Previous 2 CS & 6 & 3.7 \\
\hline D and C & 46 & 17.2 \\
\hline Previous myomectomy & 2 & 1.5 \\
\hline Previous hysterotomy & 2 & 1.5 \\
\hline MROP & 1 & 1.5 \\
\hline Endometrial biopsy & 2 & 1.5 \\
\hline
\end{tabular}




\section{Type of previa}

The occurrence of major previa in the case series (with previous obstetric interventions) was significantly higher than in the control group (without any interventions) $(55.9 \%$ vs $37.9 \%)$ and the finding was statistically significant (Figure 1).

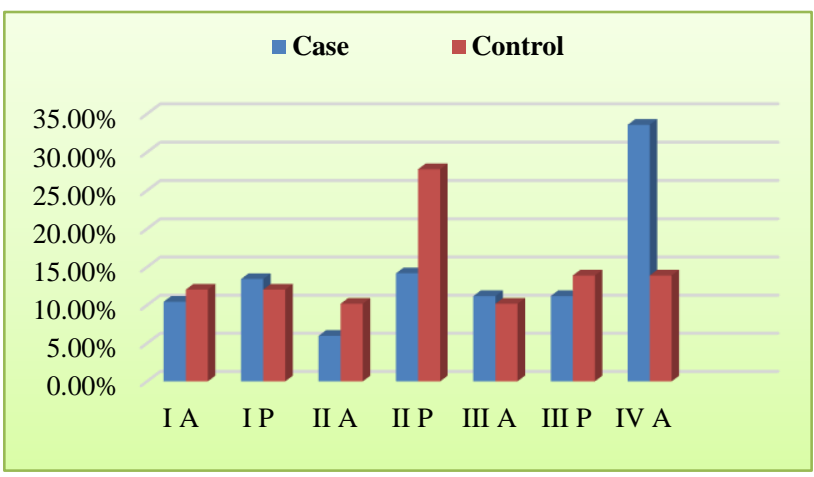

Figure 1: Type of previa.

\section{Obstetric profile}

Medical disorders like gestational hypertension, gestational diabetes, anemia, heart disease and other infections were similar in both the scarred group (cases) and non-scarred group (controls). The occurrence of antepartum haemorrhage were more in the scarred group when compared to the non-scarred group and the finding was statistically significant. Occurrence of IUGR was comparable between the 2 groups. Presentation of the fetus was mostly cephalic and it was also comparable between the 2 groups. The need for emergency LSCS was more in the scarred group compared to the non-scarred group, with $\mathrm{P}$ value 0.025 . This finding maybe due to more incidence of APH in the scarred group (cases). The findings are outlined in Table 3.

Table 3: Obstetric profile.

\begin{tabular}{|c|c|c|c|c|}
\hline Parameter & $\mathbf{P}$ & $\chi^{2}$ & OR & CI \\
\hline $\begin{array}{l}\text { Medical } \\
\text { disorders }\end{array}$ & \multicolumn{4}{|c|}{ Comparable between 2 groups } \\
\hline APH & 0.007 & 7.2 & 2.01 & $1.3-3.4$ \\
\hline IUGR & 0.989 & 0.00 & $\begin{array}{l}\text { Com } \\
\text { betw }\end{array}$ & $\begin{array}{l}\text { ble } \\
2 \text { groups }\end{array}$ \\
\hline Presentation & \multicolumn{4}{|c|}{ Comparable between 2 groups } \\
\hline $\begin{array}{l}\text { Emergency } \\
\text { termination }\end{array}$ & 0.025 & 5.05 & 1.8 & $1-3$ \\
\hline
\end{tabular}

\section{Ante-partum haemorrhage}

In both the groups, APH was the main presenting complaint which led to termination of pregnancy. Yet, history of APH was significantly higher in the cases (scarred group) as compared to controls (non-scarred group) $(58.9 \%$ Vs $41.7 \%) \chi^{2}=7.2 \mathrm{p}=0.007$ Significant. $\mathrm{OR}=2.01 \mathrm{CI}=1.3-3.4$ (Figure 2).

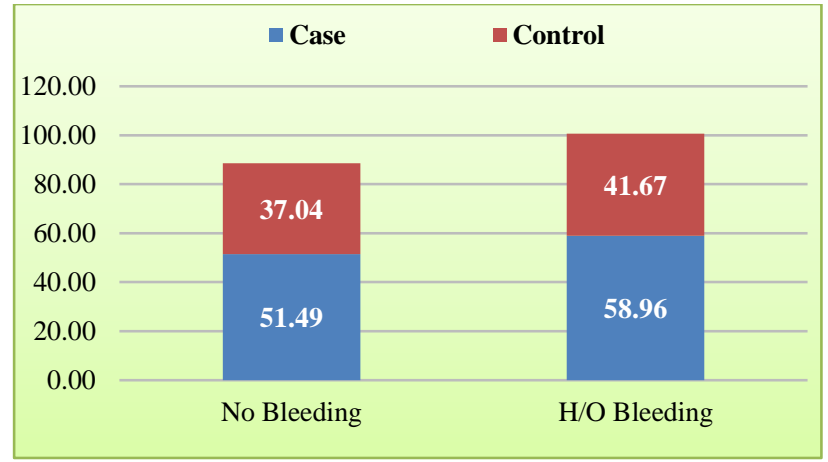

Figure 2: Ante-partum haemorrhage.

The number of episodes of APH was also more in the scarred group (cases) compared to non-scarred group (controls) with $\mathrm{P}=0.038$ and $\chi^{2}=10.2$.

\section{Gestational age and $\mathrm{APH}$}

Antepartum bleeding before 34 weeks was 3 times more in the case group as compared to the control group. $\chi^{2}=$ $5.4 \mathrm{p}=0.02$ Significant OR=3.19 CI $=1.14-8.9$ (refer Figure 3 and table 4) APH was more in the non-scarred group (controls) after 37 weeks compared to the scarred group (cases) (Figure 3).

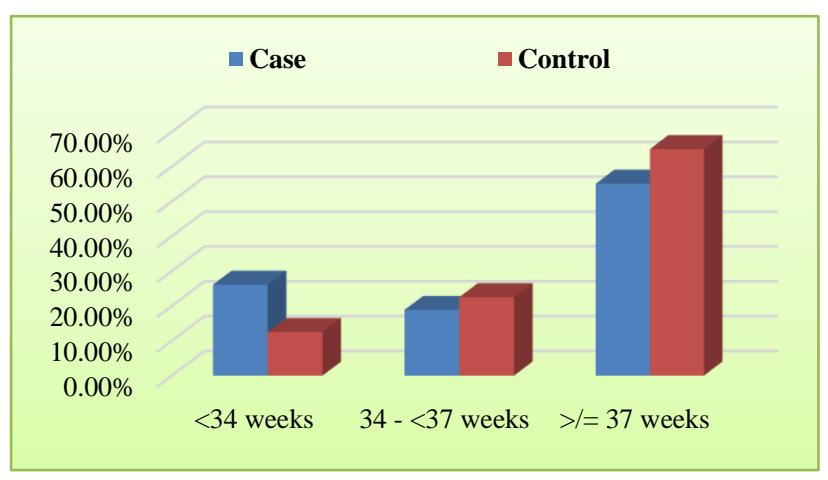

Figure 3: Gestational age of decisive bleeding.

\section{APH before 34 weeks}

Antepartum bleeding before 34 weeks was 3 times more in the case group as compared to the control group. $\chi^{2}=$ $5.4 \mathrm{p}=0.02$ Significant OR=3.19 CI $=1.14-8.9$ (Table $4)$.

Table 4: APH before 34 weeks.

\begin{tabular}{|lll|}
\hline GA $<34$ weeks & Case & Control \\
\hline APH present & $18(13.43 \%)$ & $5(4.63 \%)$ \\
\hline APH absent & $116(86.57 \%)$ & $103(95.37 \%)$ \\
\hline Total & $134(100 \%)$ & $108(100 \%)$ \\
\hline
\end{tabular}

\section{Mode of delivery}

In the scarred group (cases), the need for caesarean section was 23 times more than in the non-scarred group 
(controls). $\chi^{2}=18.1 \mathrm{p}=0.000$ Significant. $\mathrm{OR}=23.13 \mathrm{CI}=$ 3-177 (Figure 4).

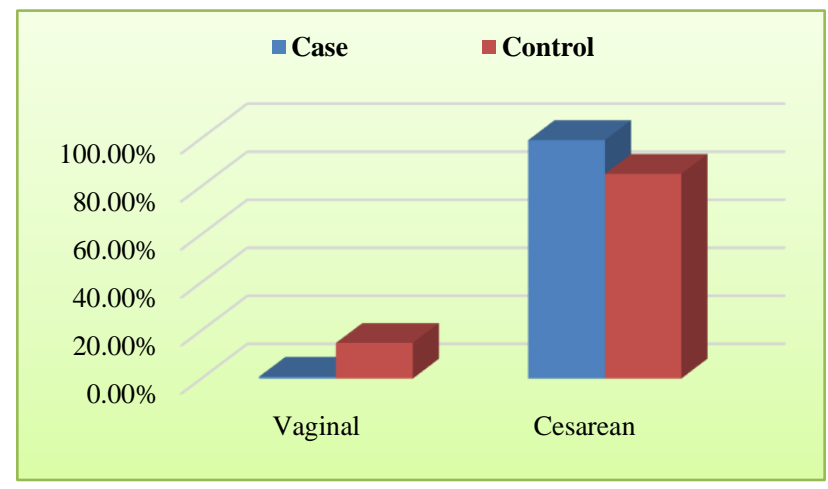

Figure 4: Mode of delivery.

Post-Partum Haemorrhage PPH was 2 times more in the scarred group compared to non-scarred group as shown in Figure 5. $\chi^{2}=11.2 \mathrm{P}=0.000$ Significant. $\mathrm{OR}=2.44$. $\mathrm{CI}=$ $1.4-4.1$.

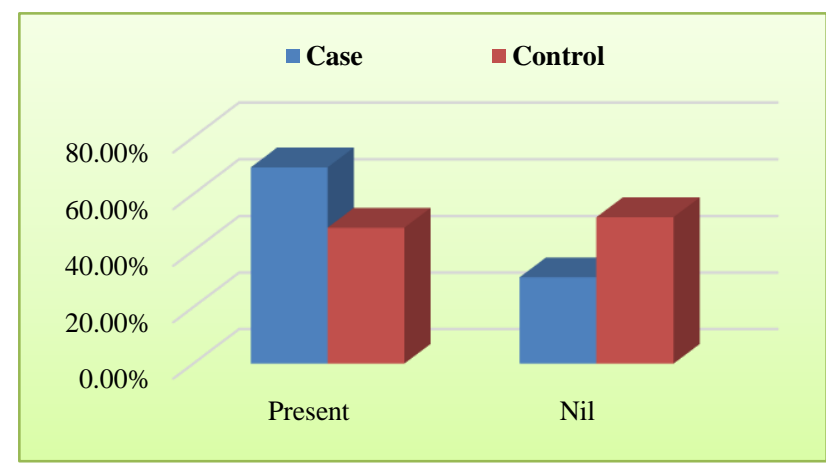

Figure 5: Post-partum haemorrhage.

Severe PPH requiring massive blood transfusions were seen entirely in the scarred group.

\section{Third stage management}

No medical management were needed in majority of the non-scarred group. Single agent (mostly oxytocin) was needed for the scarred group.

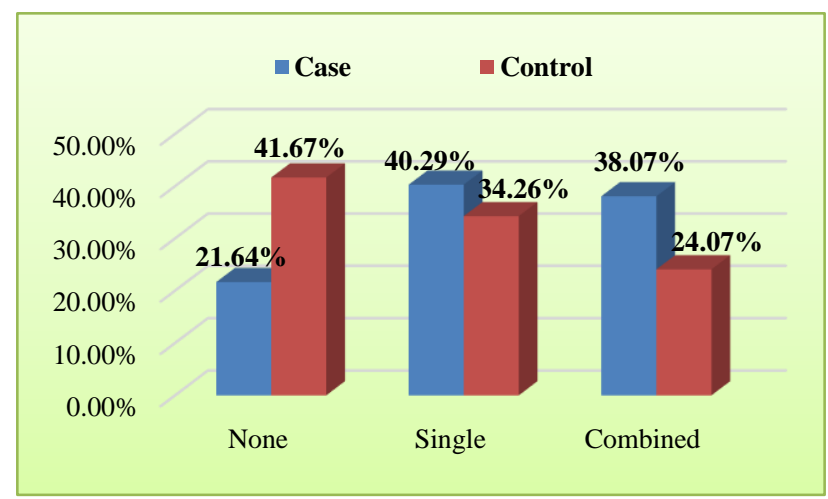

Figure 6: Need for medical management in $3^{\text {rd }}$ stage.
Need for more than one drug for the control of PPH was nearly 2 times in the scarred group when compared to the non-scarred group (Figure 6).

Need for additional operative procedures were 1.7 time more in the scarred group when compared to the nonscarred group. $\chi^{2}=4.05, \mathrm{P}=0.04$ (Significant) $\mathrm{OR}=1.7$. CI $=1.01-2.87$ caesarean hysterectomy were needed for 6 patients totally and all of them belonged to the scarred group (cases).

\section{Adherent previa}

In the scarred group, there were 8 cases of adherent placenta and none in the non-scarred group. 1 case of placenta increta, 3 placenta percreta and 4 cases of placenta accreta (Figure 7).

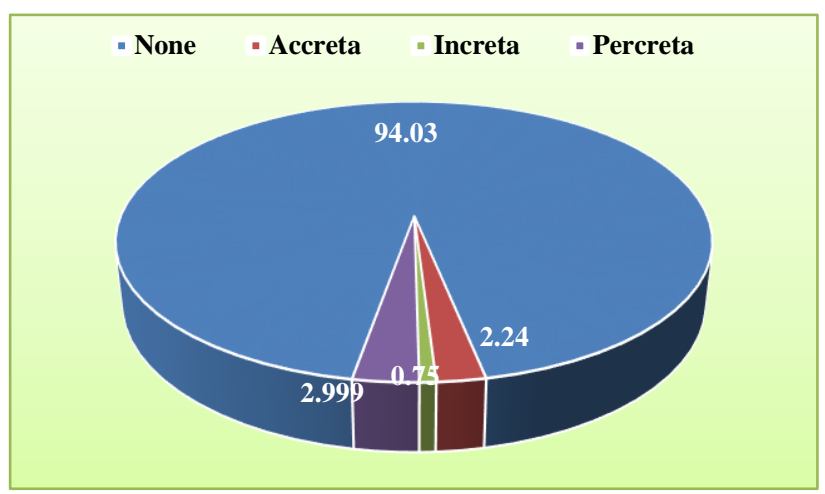

Figure 7: Placental adherence abnormalities.

\section{Intra-partum problems}

Both intraoperative and postoperative complications were more in the case group. These are listed in Table 5.

Table 5: Intra- partum problems.

\begin{tabular}{|lllll|}
\hline Parameter & $\mathrm{P}$ & $\chi^{2}$ & $\mathrm{OR}$ & $\mathrm{CI}$ \\
\hline PPH & 0.001 & 11.2 & 2.44 & $1.4-4.1$ \\
\hline $\begin{array}{l}\text { Medical Mx -Need } \\
\text { for }>1 \text { drug }\end{array}$ & 0.020 & 5.4 & 1.93 & $1-3.5$ \\
\hline $\begin{array}{l}\text { Additional surgical } \\
\text { procedures }\end{array}$ & 0.040 & 4.05 & 1.7 & $1-2.87$ \\
\hline Blood transfusion >4 & 0.010 & 6.66 & & \\
\hline $\begin{array}{l}\text { Other intra operative } \\
\text { complications }\end{array}$ & 0.006 & 7.5 & 10.53 & $1.3-8.2$ \\
$\begin{array}{l}\text { Post-operative } \\
\text { complication }\end{array}$ & 0.012 & 6.34 & 5.69 & $1.3-25.8$ \\
\hline
\end{tabular}

\section{Intra-operative complications}

Prolonged surgery $>2$ hours, bladder injury, need for massive blood transfusions, caesarean hysterectomy were all noted in the scarred group and virtually none in the non-scarred group. Bladder injury occurred in 3 cases. Detailed in Figure 8. 


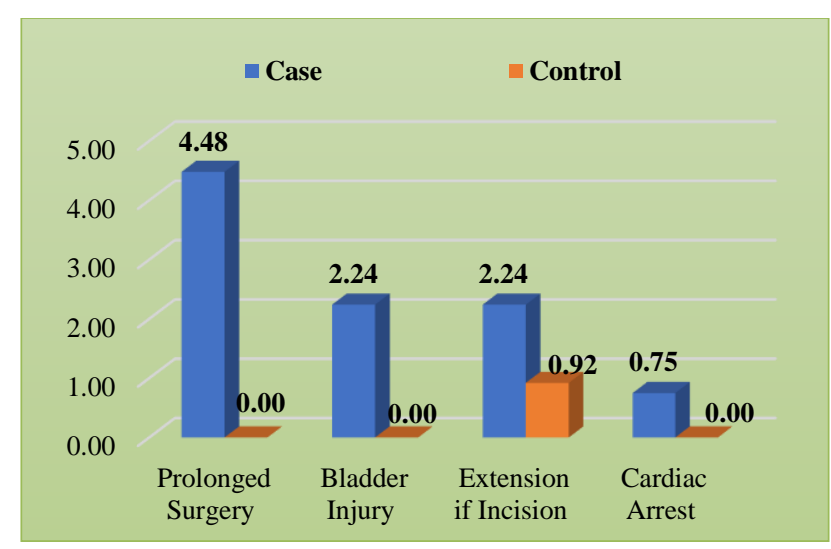

Figure 8: Intra-operative complications.

\section{Hospital stays}

Mean number of bed days in the case group was 8.47 compared to 6.62 days in the control group. $32.1 \%$ of cases had post parum stay $>7$ days compared to $6.5 \%$ of controls and the finding was statistically significant with $\mathrm{P}$ value $0.000, \chi^{2}-23.9$ and OR 6.8 (Figure 9).

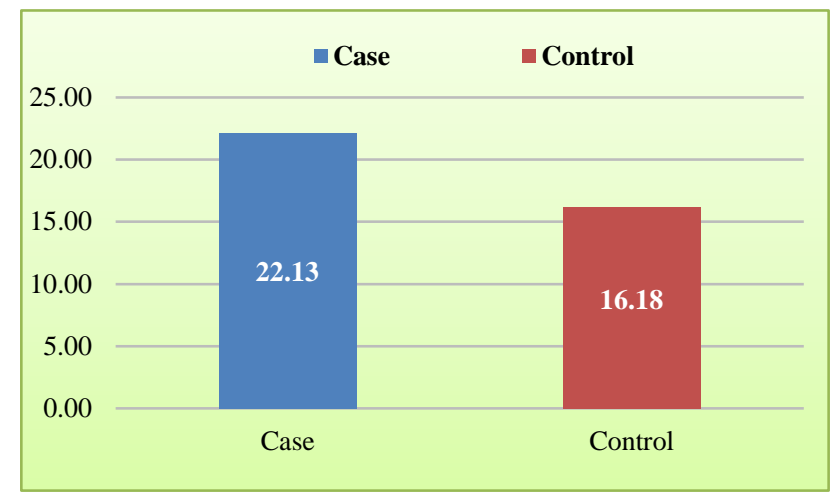

Figure 9: Mean number of bed days.

\section{DISCUSSION}

Age

Mean age in the case group was 28.4 and the control group was 25.8. Studies by Rasmussen ${ }^{5}$ showed an increase incidence with increasing age. ${ }^{5}$ Similar studies conducted by $\mathrm{Wu} \mathrm{S}$, Cleminishi et al have shown that increasing maternal age as a well known risk factor for placenta previa especially in women $>35$ yrs. ${ }^{6,7}$

\section{Parity}

Out of the 242 cases of placenta previa taken-153(63.2\%) were parous whereas $89(36.8 \%)$ cases were primigravida. Among the parous women, 119 (77.8\%) were in the case group with previous obstetric interventions as compared to $34(22.2 \%)$ in the control group without any interventions. Findings are comparable to studies conducted by Khansa et al and Reddy et al. ${ }^{8,9}$

\section{Previous obstetric interventions}

The incidence of placenta previa is more in the case series (those with previous obstetric interventions) compared to the control series (those without previous interventions). In 134 cases with previous obstetric interventions, $84(62.7 \%)$ had a scarred uterus. Studies by Taylor et al showed that women with one or more spontaneous or induced abortions are $30 \%$ more likely to have placenta previa in subsequent pregnancies. ${ }^{10}$ Studies conducted by Khansa have also shown $19.2 \%$ association of placenta previa with previous scarred uterus. ${ }^{8}$

Hershkowitz et al and Clark et al found that the incidence of placenta previa in those who had not had previous caesarean section was $0.25 \%$, with 1 scar it was $0.65 \%$ and with 3 or more it was $2.2 \% .^{11,12}$ Gilliam and colleagues also found that risk of placenta previa increases progressively as parity and number of prior caesarean deliveries increase. ${ }^{13}$ Getuhun et al in his studies have concluded a dose response pattern of risk of placenta previa with increase number of CS and a short pregnancy interval also increased the risk. ${ }^{14}$

\section{Type of previa}

The occurrence of major previa has been found to be significantly more in the case group $(55.9 \%)$ than the control group $(37.9 \%)$. Type 4 previa, in fact, was found in $33.6 \%$ of cases as compared to $13.9 \%$ of control group. This difference in the occurrence of major previa may be accounted for by the presence of scar in the uterus or endometrial curettage that has been done (along with D and C, MTP), which may cause failure of differential growth of the lower segment so that originally low lying placenta would be less likely to migrate upwards. Khansa et $\mathrm{al}^{8}$ in his study found $19.2 \%$ association placentaprevia with previously scarred uterus.

\section{Number of episodes of APH}

The occurrence of recurrent episodes of antepartum haemorrhage was significantly greater (2 times) in the case group than in the control group. This may be due the greater number of higher degree placenta previa in the case group than the control group.

\section{Gestational age at which decisive bleeding has occurred}

When APH before 34 weeks is considered, a statistically significant difference exists between cases and control group with more number of placenta previa in case group compared to controls ( 3 times). This may be due to higher degrees of previa and earlier detachment from previous scar in the case group.

\section{Mode of delivery}

Regarding the mode of delivery, the need for caesarean section was 23 times more in the case series than in the 
control series. Caesarean sections were significantly greater in the case group due to following reasons.

- Larger number of Type III and Type IV previa in case group.

- Greater incidence of APH in the case series.

- Larger number of abnormal presentations in case group (though statistically not significant).

- Indicated due to the patient having a scarred uterus.

\section{Postpartum haemorrhage}

PPH was 2 times more common in the case group than in the control group. Moreover, severe PPH exclusively occurred in the case group. This may be due to larger number of type 3 and 4 previa in the case group, greater incidence of APH in the case group, increased incidence of atonicity in the scarred uterus. Studies by Khansa ${ }^{8}$ showed that incidence of PPH was significantly higher in the scarred group. His findings were consistent with studies by Zelop et al. ${ }^{15}$

\section{Placental adherence abnormality}

All cases of adherent placenta were in the case series, clearly showing the importance of placenta previa in a scarred uterus as compared to the control group. Presence of adherence of placenta in case group was statistically significant. The reported incidence of prior caesarean section in women with placenta previa accreta is from $43 \%-60 \%$ (Clark et al 1985). Mcshane et al ${ }^{16}$ reported that of the 22 women in their series with a previous caesarean section scar, six $(27 \%)$ had placenta accreta. The risk of placenta accreta is linearly related to the number of previous uterine scars (usually caesarean sections) in the presence of a placenta previa (Clark et al).

\section{Intraoperative complications}

When $3^{\text {rd }}$ stage management with drugs is considered, the use of more than one drug was 2 times higher in the case group which was because of the increased PPH in the case group.

\section{Additional operative procedure}

The need for additional operative procedures for control of PPH like uterine artery ligation, ovarian artery ligation, internal iliac ligation and obstetric hysterectomy, were needed 1.7 times more in the case group. Wong et al, Parkland hospital found that morbidly adherent placenta with previa is the most frequent indication for postpartum hysterectomy. ${ }^{17}$

Studies by Gyamfi et al also suggests that women with accrete syndromes have increased risk for uterine rupture, previa and hysterectomy. ${ }^{18}$ High incidence of hysterectomy in such patients have also been found by Esakoff et al in his studies. ${ }^{19}$ Studies by Khansa has shown an incidence of peripartum hysterectomy of $57.5 \%$ in the scarred group compared to $5.8 \%$ in the unscarred. ${ }^{8}$ Whereas massive blood transfusion was entirely limited to the case group, even large number of blood transfusions (of $>4$ ) was solely needed for the case group. Requirement of blood and blood products were significantly higher in the adherent placenta group in studies conducted by Knight et al. ${ }^{20}$ Studies by Khansa showed $10 \%$ of patients with scarred uterus needed massive blood transfusion compared to no patients in the unscarred group. ${ }^{8}$ Findings were similar in studies by CC Umezurike. $^{21}$

\section{Complications}

Both intraoperative and postoperative complications like prolonged surgery, bladder injury, extension of incision, ICU admissions, UTI etc were found to be more in the case series

\section{Duration of hospital stay}

Mean duration of hospital stay is more for the case group. This is statistically significant too. Majority of patients in the case group $(72.4 \%)$ had to stay for $>10$ days in the hospital. Postpartum hospital stay is significantly higher (almost 7 times) for the case group as compared to control group. This may be due to increase number of maternal complications like bladder injury, secondary $\mathrm{PPH}$, higher number of IBN admissions for babies in the case group.

\section{CONCLUSION}

From this study, it is very evident that antepartum haemorrhage is more in cases of placenta previa with previous obstetric interventions. Recurrent episodes as well as early occurrence of antepartum haemorrhage are found to be more in cases of placenta previa with previous obstetric interventions than in those without.

Intrapartum complications, the need for larger number of blood transfusions, occurrence of postpartum haemorrhage, the need to use more than one drug during third stage management, the need for additional operative procedures including hysterectomy for control of PPH, postpartum morbidity were significantly more in the case group.

Thus, we may conclude that the occurrence of placenta previa in a patient with previous obstetric intervention needs to be managed in a tertiary care centre with all facilities available, for a good maternal and neonatal outcome. Early referral of these patients to a tertiary care centre is always preferable.

Funding: No funding sources Conflict of interest: None declared

Ethical approval: The study was approved by the Institutional Ethics Committee 


\section{REFERENCES}

1. Brace V, Kernaghan D, Penney G. Learning from adverse clinical outcomes: major obstetric haemorrhage in Scotland, 2003-05. BJOG: Int J Obstet Gynecol. 2007 Nov 1;114(11):1388-96.

2. Mathuriya G, Lokhande P. Comparative study of obstetrics outcome between scarred and unscarred uterus in placenta previa cases. Indian J Clin pract. 2013;24(6):568-571.

3. Faiz AS, Ananth CV. Etiology and risk factors for placenta previa: an overview and meta-analysis of observational studies. J Maternal-Fetal Neonat Med. 2003 Jan 1;13(3):175-90.

4. Dashe JS, McIntire DD, Ramus RM, Santos-Ramos R, Twickler DM. Persistence of placenta previa according to gestational age at ultrasound detection. Obstet Gynecol. 2002 May 31;99(5):692-7.

5. Rasmussen S, Albrechtsen S, Dalaker K. Obstetric history and the risk of placenta previa. Acta Obstetricia et Gynecologica Scandinavica. 2000 Jun 1;79(6):502-7.

6. Wu S, Kocherginsky M, Hibbard JU. Abnormal placentation: twenty-year analysis. American journal of obstetrics and gynecology. 2005 May 31;192(5):1458-61.

7. Cieminski A, Długołecki F. Relationship between placenta previa and maternal age, parity and prior caesarean deliveries. Ginekologia Polska. 2005 Apr;76(4):284-9.

8. Iqbal K, Abid R, Irfan R, Shaheen F. Comparison of Fetomaternal Outcome Between Scarred and Unscarred Uterus in Placenta Parevia Cases. J Soc Obstet Gynecol Pak. 2016;6(3):102.

9. Reddy R, Latha C. Placenta previa: an analysis of 4 year experience. J Obstet Gynecol India. 1999:53-6.

10. Taylor VM, Kramer MD, Vaughan TL, Peacock S. Placenta Previa in Relation to Induced and Spontaneous Abortion: A Population-Based Study. Obstet Gynecol. 1993 Jul 1;82(1):88-91.

11. Hershkowitz R, Fraser D, Mazor M, Leiberman JR. One or multiple previous caesarean sections are associated with similar increased frequency of placenta previa. Eur J Obstet Gynecol Reprod Biol. 1995 Oct $1 ; 62(2): 185-8$.
12. Clark SL, Koonings PP, Phelan JP. Placenta previa/accreta and prior caesarean section. Obstet Gynecol. 1985 Jul 1;66(1):89-92.

13. Gilliam M, Rosenberg D, Davis F. The likelihood of placenta previa with greater number of caesarean deliveries and higher parity. Obstet Gynecol. 2002 Jun 30;99(6):976-80.

14. Getahun D, Oyelese Y, Salihu HM, Ananth CV. Previous caesarean delivery and risks of placenta previa and placental abruption. Obstet Gynecol. 2006 Apr 1;107(4):771-8.

15. Zelop CM, Harlow BL, Frigoletto FD, Safon LE, Saltzman DH. Emergency peripartum hysterectomy. American J Obstet Gynecol. 1993 May $1 ; 168(5): 1443-8$.

16. McShane PM, Heyl PS, Epstein MF. Maternal and perinatal morbidity resulting from placenta previa. Obstet Gynecol. 1985 Feb 1;65(2):176-82.

17. Wong TY. Emergency peripartum hysterectomy: a 10 -year review in a tertiary obstetric hospital. The New Zealand Med J (Online). 2011 Nov 4;124(1345).

18. Gyamfi-Bannerman C, Gilbert S, Landon MB, Spong CY, Rouse DJ, Varner MW et al. Risk of uterine rupture and placenta accreta with prior uterine surgery outside of the lower segment. Obstet Gynecol. 2012 Dec;120(6):1332.

19. Esakoff TF, Handler SJ, Granados JM, Caughey AB. PAMUS: placenta accreta management across the United States. J Maternal-Fetal Neonat Med. 2012 Jun 1;25(6):761-5.

20. Knight M. Peripartum hysterectomy in the UK: management and outcomes of the associated haemorrhage. BJOG: Int J Obstet Gynecol. 2007 Nov 1;114(11):1380-7.

21. Umezurike CC, Feyi-Waboso PA. Placenta accreta and the developing world-A review. East Afr Med J. 2010;87(12):513-20.

Cite this article as: Nair DB, Murukesan L, Menon $\mathrm{S}$. The effect of previous obstetric interventions in the outcome of placenta previa. Int J Reprod Contracept Obstet Gynecol 2017;6:4879-85. 